ISCKMC 2020

International Scientific Congress «KNOWLEDGE, MAN AND CIVILIZATION»

\title{
DYNAMICS OF THEORETICAL KNOWLEDGE ON THE THEORY AND METHODOLOGY OF PHYSICAL EDUCATION
}

\author{
Salman Baysultanovich Elipkhanov (a)*, Kilab Shamsudinovich Dunaev (b), \\ Asvad Adamovich Tsetiev (c), Madina Alkhazurovna Alieva (d) \\ *Corresponding author
}

(a) Chechen State Pedagogical University, H. Isaeva ave., 62, Grozny, 364068, Russia, sbelphnv@mail.ru,

(b) Chechen State Pedagogical University, H. Isaeva ave., 62, Grozny, 364068, Russia, dunaev-1954@mail.ru,

(c) Chechen State Pedagogical University, H. Isaeva ave., 62, Grozny, 364068, Russia, cetiev.asvad@mail.ru, (d) Chechen State Pedagogical University, H. Isaeva ave., 62, Grozny, 364068, Russia, m.alieva_madina@inbox.ru

\begin{abstract}
This scientific research article deals with the problem of monitoring of growth dynamics of knowledge of the basic theory and methodology of physical education. The article addresses the growth dynamics of the level of knowledge acquisition using a longitudinal study within two years at the Faculty of Physical Education and Sports of Chechen State Pedagogical University. The research aims to determine the growth of knowledge within two years of study and application of additional efficient means and methods for the knowledge increase. A questionnaire survey was conducted using a questionnaire with closeended questions and rating scales. Prior to the survey the students were informed about purpose, goals and importance of the experiment. The survey was conducted in four stages. Between the stages a broad spectrum of teaching methods was used such as a reproductive one, a frontal one, a group one, an individual one, a mixed one, etc. Also some off-hour classes were applied such as participation in the ongoing seminar, round-tables, conferences, writing library-research papers, essays, reports, participation in a grant-project activity in the scientific field. The final survey showed a significant growth of knowledge on the basic theory and methodology of physical education. It is discovered that searching of means and methods for knowledge quality increase with use of monitoring and acceptance of modern pedagogical operations gives a positive result.
\end{abstract}




\section{Introduction}

The goal of higher educational institutes is development of innovation educational system technologies that are based on advanced results of scientific research. Teachers' goal is searching for new means, methods and directions for improvement of knowledge quality in students (Chervyakova \& Kivikhariyu, 2014; Urazbekov, 2018). In this regard it's necessary to use knowledge monitoring in the format of longitudinal study. With the existing system for determining knowledge using intermediate and final examination at a higher educational institute, the question of studying the dynamics of the quality of acquiring knowledge by students remains open. There is a dynamics, the logic of substantiation of growth and a possibility of immediate intervention in the process of acquiring and improving knowledge (Kholodov \& Kuznetsov, 2004).

\section{Problem Statement}

Theory and methodology of physical education are the major subject for specialists in the field of the physical education. One of the essential parts of expertise is successfulness of competences shaped on the given subject. The quality of developing a student into a professional depends on how consciously and regularly the student will acquire the knowledge (Orlova et al., 2018).

Monitoring of successfulness of knowledge of a subject is an important factor in knowledge acquisition. Determining the dynamics of growth of theoretical knowledge will allow making correction in the teaching methodology and taking management decisions related to the subject.

\section{Research Questions}

The longitudinal study of the dynamics of knowledge acquisition on the teaching subject of "Theory and Methodology of Physical Education" was conducted at the Faculty of Physical Education and Sports of Chechen State Pedagogical University (Stolyarov, 2007). A questionnaire consisted of 25 questions underlining theoretical basics of the teaching subject. The questions were of close-ended type having one correct answer out of three presented choices. The first questionnaire survey was conducted in September (see table 1), in early academic year, among third-year students of the Faculty of Physical Education and Sports.

The questionnaire survey took place in a standard lecture hall and the students were given 30 minutes for answering the questions. For evaluation of the questionnaire results we applied the five-point grading scale, developed by us, which evaluated the answers as follows: 0 to $10=2$ points, 11 to $16=3$ points, 17 to $20=4$ points and 21 to $25=5$ points. 
Table 1. Results of the questionnaire survey on knowledge of basics of theory and methodology of physical education (September 2018)

\begin{tabular}{ccccccc}
\hline & & \multicolumn{5}{c}{ Results } \\
\cline { 3 - 7 } & $\underset{n}{\text { Year }}$ & 5 points $/ \%$ & 4 points $/ \%$ & 3 points $/ \%$ & 2 points $/ \%$ & $\frac{\text { Number of }}{\text { respondents }}$ \\
\hline 1 & Third-year & - & $4 / 20 \%$ & $15 / 75 \%$ & $1 / 5 \%$ & $\mathrm{n}=20$ \\
2 & Points & - & 16 & 45 & 2 & 63 \\
\hline
\end{tabular}

*Note: - total points: the number of respondents is multiplied by the achieved points and equals the number of points for the group, by simple addition - the total number for a year.

Conducting the questionnaire survey for the purpose of studying the dynamics of growth of knowledge on the teaching subject in September, the beginning of the academic semester, was grounded on the necessity to test the retained knowledge that stick to the students' minds. The survey results showed a growth in the test parameters: the number of students who received an "excellent" grade remained unchanged, however this time we managed to avoid the "unsatisfactory" grade. The percentage of students who got a "good" grade (70\%) has increased significantly as compared to the previous survey (45\%). The statistics says about positive dynamics of growth of knowledge of the students (Firsin \& Lipskiy, 2018).

The research objective is determining the dynamics of growth of theoretical knowledge on the subject of "Theory and Methodology of Physical Education" as a part of the longitudinal study (Semenov, 2011).

According to the survey results, none of the respondents got an "excellent" grade, $75 \%$ of respondents got a "satisfactory" grade, and one respondent got an "unsatisfactory" grade. The first questionnaire survey proves that the third-year students have a certain scope of knowledge based on information they learned in previous years on the subjects of physical education.

Realizing relevance of the subject of "Theory and Methodology of Physical Education" in development of a competent specialist in the field of physical education, a broad spectrum of teaching methods was applied such as an individual one, a group one, a frontal one, a mixed one, a reproductive one, a problematic one, etc. A special focus was on the terminology, conceptual framework and logical comprehension of relevance of the subject itself for the further career of a future specialist. The students made notes, reviewed, wrote essays on relevant topics.

By the end of the examination period in December 2018 the second questionnaire survey was conducted among the third-year students (see table 2).

Table 2. Results of the questionnaire survey on knowledge of basics of theory and methodology of physical education (December 2018)

\begin{tabular}{ccccccc}
\hline \multirow{2}{*}{$\mathrm{N}$} & Year & \multicolumn{5}{c}{ Results } \\
\cline { 3 - 7 } & Points & 5 points $/ \%$ & 4 points $/ \%$ & 3 points $/ \%$ & 2 points $/ \%$ & $\frac{\text { Number of respondents }}{\text { Total points* }}$ \\
\hline 1 & Third-year & $1 / 5 \%$ & $9 / 45 \%$ & $9 / 45 \%$ & $1 / 5 \%$ & $\mathrm{n}=20$ \\
2 & Points & 5 & 36 & 27 & 2 & 70 \\
\hline
\end{tabular}

*Note: - total points: the number of respondents is multiplied by the achieved point and equals the number of points for the group, by simple addition - the total number for a year. 
Conducting the questionnaire survey in December was justified by the fact that the level of knowledge on the subject would be a priori higher as compared to the beginning of the examination period. In fact the survey results expressed both in percentage and points ( 7 points) turned out to be not high. Supposedly we did not manage to reveal objectively their retained knowledge due to the preexamination stress level caused by preparations for other exams.

The next questionnaire survey was conducted in early September 2019 with the same list of students (quantitatively) (see table 3).

Table 3. Results of the questionnaire survey on knowledge of basics of theory and methodology of physical education (September 2019)

\begin{tabular}{ccccccc}
\hline \multirow{2}{*}{$\mathrm{N}$} & \multirow{5}{*}{ Year } & \multicolumn{5}{c}{ Results } \\
\cline { 3 - 7 } & Points & 5 points $/ \%$ & 4 points $/ \%$ & 3 points / \% & 2 points / \% & $\frac{\text { Number of respondents }}{\text { Total points* }}$ \\
\hline 1 & Fourth-year & $1 / 5 \%$ & $14 / 70 \%$ & $5 / 25 \%$ & - & $\mathrm{n}=20$ \\
2 & Points & 5 & 56 & 15 & - & 76 \\
\hline
\end{tabular}

*Note: - total points: the number of respondents is multiplied by the achieved point and equals the number of points for the group, by simple addition - the total number for a year

\section{Purpose of the Study}

Improving quality of knowledge on the basic theory and methodology of physical education. The goals are:

1. to provide a theoretical rationale of a need to monitor students' knowledge on basics of the subject of "Theory and Methodology of Physical Education";

2. to reveal dynamics of growth of theoretical knowledge in students within two years in the process of their tuition;

3. to substantiate the study results based on the analysis and the experiment conducted and feasibility of application of means and methods to improve the results.

\section{Research Methods}

Conducting the questionnaire survey for the purpose of studying the dynamics of growth of knowledge on the teaching subject in September, the beginning of the academic semester, was grounded on the necessity to test the retained knowledge that stick to the students' minds (Rusakova et al., 2015). The survey results showed a growth in the test parameters: the number of students who received "excellent" grade remained unchanged, however this time we managed to avoid the "unsatisfactory" grade. The percentage of students who got a "good" grade $(70 \%)$ has increased significantly as compared to the previous survey (45\%). The statistics says about positive dynamics of growth of knowledge in the students (Elipkhanov et al., 2017).

The fourth-year students in addition to their educational classes on the subject of "Theory and Methodology of Physical Education" attended a students' scientific group called "Scientific and Methodological Framework of Physical Education", participated in round-table discussions and 
conferences and also attended consultations of the ongoing seminar on the subject of physical education from September on. Examination questions on the subject were distributed in early October (Ivankov, 2014). On the threshold of the examination period the fourth-year students attended four summarizing lectures given to the fifth-year students as a part of preparation for the final national exam.

The final questionnaire survey was conducted in late December 2019 observing all methodological requirements (see table 4). 20 fourth-year students were involved in the survey.

Table 4. Results of the questionnaire survey on knowledge of basics of theory and methodology of physical education (December 2019)

\begin{tabular}{|c|c|c|c|c|c|c|}
\hline \multirow[b]{2}{*}{$\mathrm{N}$} & \multirow[b]{2}{*}{$\frac{\text { Year }}{\text { Points }}$} & \multicolumn{5}{|c|}{ Results } \\
\hline & & 5 points $/ \%$ & 4 points / $\%$ & 3 points $/ \%$ & 2 points $/ \%$ & $\frac{\underline{\text { Number of }}}{\text { respondents }}$ \\
\hline 1 & $\begin{array}{c}\text { Fourth- } \\
\text { year }\end{array}$ & $7 / 35 \%$ & $13 / 65 \%$ & - & - & $\mathrm{n}=20$ \\
\hline 2 & Points & 35 & 52 & - & - & 87 \\
\hline
\end{tabular}

*Note: - total points: the number of respondents is multiplied by the achieved point and equals the number of points for the group, by simple addition - the total number for a year

\section{Findings}

When analyzing the questionnaire survey on the subject of basic theory and methodology of physical education, we revealed significant changes in the growth of knowledge - those who got an "excellent" grade were found to be $35 \%$, and those who got a "good" grade were $65 \%$; no "satisfactory" and "unsatisfactory" grades were gotten.

According to the Charter of the point rating system of the rating point conversion scale into the five-mark grading system approved in the University, the students after summation got an average grade 87 which, if converted into a five-mark grading system, means "excellent". Results of the first survey showed a low level of knowledge in the third-year students. It can be explained by the fact that their specialization was planned for the next academic years. The second and third surveys showed a weak growth which gave a reason for taking active management decisions about necessity of additional application of intensive education methods. The third survey resulted in high percent (70\%) of "good" grades. Prior to the final survey some extra training forms on the principal subject were applied in addition to the class-hours. During the final academic assessment, the students were preparing for an examination on the subject, and possibly the point rating system also had its effect.

\section{Conclusion}

1. The first stage of the study revealed a low level of knowledge on the subject of the basic theory and methodology of physical education.

2. The second and third stages of the study revealed a weak but positive dynamics of growth of knowledge in the students. 
3. The survey at the fourth stage of the study showed significant growth of knowledge on the subject of the basic theory and methodology of physical education.

4. The study findings suggest that with the purposeful, systematically correct and methodically right approach it becomes possible to have dynamics of growth of knowledge in the students of the Faculty of Physical Education and Sports.

\section{References}

Chervyakova, E. E., \& Kivikhariyu, I. V. (2014). Problems of physical education in educational institutions at the present stage. Tsarskoye Selo reading, 1, 228-232.

Elipkhanov, S. B., Batukaev, A. A., \& Tsetiev, A. A. (2017). Meaning of theoretical knowledge on the subject of "Physical Education" in constant education of schoolchildren and students. Sci. notes of P.F. Lesgaft Univer., 12(154), 316-319.

Ivankov, C. T. (2014). Theory, methodology and practice of physical education. Textbook for students of higher and secondary educational institutions of physical education and sport. Moscow State Pedag. University. http://www.iprbookshop.ru/70024.html

Firsin, S. A., \& Lipskiy, E. V. (2018). Physical education teachers' approach to different innovative programs, technologies, techniques. Modern probl. of sci. and ed., 5, 123.

Kholodov, J. K., \& Kuznetsov, V. S. (2004). Theory and methodology of physical education. Textbook for students of higher and secondary schools of physical education (3rd ed.). Publ. Center "Academy".

Orlova, E. A., Zhukov, R. D., \& Pirog, A. A. (2018). Information and Communication Technologies in Physical Education: informative content of work programs. Integrated communicat. in sports and tourism: format., tendency, int. experience, 2, 133-136.

Rusakova, N. G., Gorelik, V. V., \& Semiglazova, E. P. (2015). Modern problems of physical education of students in higher education. In Major aspects of psychology, pedagogy and education. Coll. of sci. papers follow. the results of the int. sci.-pract. conf. (pp. 97-99). Samara.

Semenov, L. A. (2011). Introduction to research activities in the field of physical education and sports. Textbook. Soviet Sport. http://www.iprbookshop.ru/16818.html

Stolyarov, V. I. (2007). Conceptual crisis in the sciences of physical education and sport: indicators, causes and ways to overcome. Theory and pract. of phys. Ed., 12, 59-62.

Urazbekov, Z. S. (2018). Features of planning for the subject of physical education in the framework of updated educational programs. Latest sci. res. in the modern world, 11-7(43), 94-97. 